\title{
Age-dependent immune events during HBV infection from birth to adulthood: an alternative interpretation
}

\author{
Antonio Bertoletti ${ }^{1,2}$ * and Michelle Hong ${ }^{1,2}$ \\ 1 Emerging Infectious Diseases (EID) Program, Duke-NUS Graduate Medical School, Singapore \\ ${ }^{2}$ Viral Hepatitis Laboratory, Singapore Institute for Clinical Sciences, Agency of Science Technology and Research (A*STAR), Singapore
}

\section{Edited by:}

Arnaud Marchant, Université Libre de

Bruxelles, Belgium

\section{Reviewed by:}

Nejat K. Egilmez, University of

Louisville, USA

Ed Clarke, MRC Unit - The Gambia,

Gambia

\section{${ }^{*}$ Correspondence}

Antonio Bertoletti, Emerging

Infectious Diseases (EID) Program,

Duke-NUS Graduate Medical School,

8 College Road, Singapore 169857

e-mail: antonio@duke-nus.edu.sg
Immune responses change during the life of an individual. While this concept has been well accepted for adaptive immunity, only recently it is becoming clear that the innate immune responses also acquire distinct features in different phases of life. We believe that this concept can offer a different interpretation of the pathological manifestations that can be observed in HBV-infected subjects during the patient's life. Here, we will review the age-related immunopathological features of HBV infection and discuss how the different virological and clinical manifestations might be linked to the developmental pathway of the immune system from newborns to adults. We will discuss how the age of patients can affect the degree of inflammatory responses, but not the levels of antiviral specific immunity. We then propose that the different clinical manifestations occurring during the natural history of HBV infection are related to the host ability to trigger an inflammatory immune response.

Keywords: HBV infection, vertical transmission, immune tolerance, liver inflammation, antiviral immunity
Hepatitis B virus is a hepatotropic, non-cytopathic, DNA virus that chronically infects about 300 million people worldwide. It causes acute or chronic liver diseases characterized by different levels of liver inflammation and viral replication. An acute HBV infection can be resolved without clinical symptoms or with an inflammatory disease of the liver (acute hepatitis). Similarly, persistent HBV infection can cause minimal pathological manifestations or trigger a chronic liver inflammation that develops into liver cirrhosis or cancer (1). These clinical and virological profiles do not only vary among individuals in relation to their genetic background, dose, or route of infection but they are also present within the same individual in relation to his age.

HBV chronic infection is, particularly in Asia, the result of virus transmission from $\mathrm{HBV}^{+}$mothers to their infants (1). $\mathrm{HBV}$ infection at birth is characterized by an apparent benign phase of disease with high HBV replication levels and absence of markers of liver inflammation [i.e., normal alanine aminotransferase or aminotransferases (ALT) levels; an enzyme released by dying hepatocytes] during childhood. This phase, defined as immune tolerant, is followed by a disease phase in adulthood characterized by liver inflammatory events and fluctuations in ALT levels and viral load, known as the immune active/clearance phase (Figure 1) $(1,2)$. The favored interpretation of these different virological and clinical patterns is that during childhood there is a phase of immunotolerance, i.e., an absence of antiviral specific immunity that is lost at the start of adulthood when the host immune system actively "combat" HBV infection (2).

Here, we will review the data that dispute this scenario and propose an alternative interpretation of these immunopathological events based on the new understanding of the age-related immunological changes.

\section{HBV VERTICAL INFECTION: DOES IT INDUCE IMMUNE TOLERANCE?}

The influence of age on HBV infection starts at birth. Take, for example, acute hepatitis B infection. In infants or children, HBV infection rarely causes acute hepatitis (2), while in adults, acute hepatitis B infection is common and is almost invariably associated with HBV control due to the induction of an efficient HBV-specific $\mathrm{T}$ - and B-cell response (3). Vertical (mother-to-child) infection in infants often leads to chronic diseases (in $90 \%$ of infection) and it is thought that the establishment of a persistent infection is due to immaturity of the neonatal immune system and/or the induction of "immunotolerance," i.e., the inability to induce a virus-specific immune response (2).

This infant's inability to mount HBV-specific T- and B-cell responses is supported mainly by data from animal models (i.e., HBV transgenic mice) that showed the presence of immunological defects, which impair HBV-specific T- and B-cell priming in neonatal animals (4-6). These data are methodologically robust. Nevertheless, their significance in relation to HBV pathogenesis can be questionable, since in HBV transgenic mice, HBV does not infect the mouse hepatocytes but viruses are produced through the introduction of HBV-DNA in the mouse genome under the control of hepatocyte-specific promoters $(7,8)$. As such, the possibility that HBV infection might induce priming of adaptive immunity or activation of innate immunity is excluded "a priori."

The concept that neonates have a "defective" immune system is also changing and mounting evidences show that the neonatal immune responses defy such simple categorization. Indeed, recent studies have demonstrated that the immune effectors as well as regulatory responses are already in place during early fetal life $(9,10)$. Furthermore, newborns have been shown to mount a virus-specific $\mathrm{T}$ cell response toward viral infections in early life 

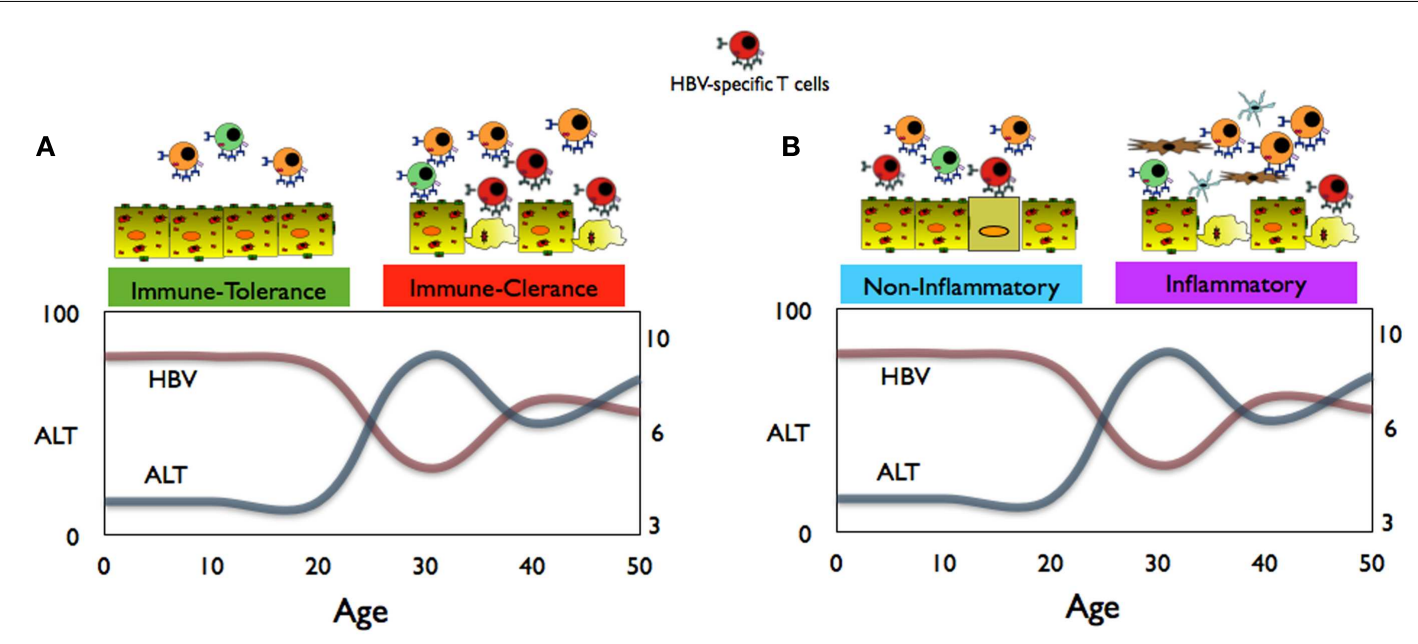

FIGURE 1 | (A) Conventional schematic representation of immune events, HBV replication, and aminotransferases (ALT) levels in children and adults during chronic HBV infection. (B) Proposed interpretation of the immune events during the non-inflammatory and inflammatory phases of CHB infection.

(11-13). Besides, exposure of the newborn immune system toward microbes at birth can also modulate the maturation status of the newborn infant. Epidemiological observations and experimental data have shown that bacterial colonization and/or immunization can protect infants against unrelated pathogen infection by inducing an increased functional efficiency of their innate immune system, a process termed "trained immunity" (14). All these earlier reports show that the newborn infant's immune system is not "defective" per se; rather, we believe that it is less prone to trigger a full blown pro-inflammatory reaction, likely as an evolutionary adaptation to avoid undesirable immune reactions in utero (15).

Therefore, the hypothesis that vertical HBV infection in infants leads to the induction of immunotolerance remains controversial. Even though the immunological data both during and after natural vertical HBV infection are limited, there are several epidemiological and experimental evidences that contradict the immunotolerance hypothesis during vertical HBV infection. For example, it has been reported that dendritic cell functionality is normal or minimally altered in neonates of $\mathrm{HBV}^{+}$mothers $(16,17)$ and the detection of $\mathrm{T}$ cells specific for $\mathrm{HBV}$ in two independent studies performed in $\mathrm{HBsAg}^{-}$children born from $\mathrm{HBV}^{+}$ mothers $(18,19)$ show that neonates exposed to HBV do not necessarily develop a defect in $\mathrm{T}$ cell priming but can mount a HBV-specific T cell response. The increase detection of HBV quasispecies in immunotolerant $\mathrm{HBV}^{+}$children is compatible with the presence of an immune pressure (20) and not with tolerance. Similarly, the efficacy of $\mathrm{HBV}$ vaccination in children born to $\mathrm{HBV}^{+}$ mothers $(21,22)$ and the better outcome of standard treatment detected in $\mathrm{HBV}^{+}$children $(23,24)$ are at odds with the general idea of immunotolerance in HBV-infected children. Similarly, the "immunotolerance" hypothesis is difficult to reconcile with epidemiological evidences that HBV-related fulminant hepatitis is more frequent in children of $<1$ year of age compared to older subjects (25) or with the observations obtained from malaria-HBV co-infected young patients in whom reduced parasitemia (26) and increased incidences of cerebral malaria (27), a Th1-mediated malaria complication, have been reported. This latter observation is perhaps more in line with the possibility of an alternative relationship between $\mathrm{HBV}$ and humans during early life.

We have started to investigate the immunological parameters in the cord blood of newborns of $\mathrm{HBV}^{+}$mothers. Characterization of these samples is complex since it is difficult to understand due to ethical considerations whether neonates are infected by HBV (i.e., HBV replication in the hepatocytes) or are only exposed to it (i.e., HBV is present in the circulation but is not able to establish an infection in hepatocytes). Nevertheless, our preliminary data on cytokine analysis of the sera from neonates born to $\mathrm{HBV}^{+}$mothers reveal a cytokine signature compatible with a Th1-like response (i.e., high levels of IL-12p40 and low levels of Th2/suppressive cytokines IL-4, IL-5, IL-13, and IL-10) and a reduced pro-inflammatory cytokine profile (i.e., lower levels of IL-1b and IL-6) (manuscript in preparation). This Th1 cytokine signature is more suggestive of a possible symbiotic relationship between HBV and humans during early life, similar to the one demonstrated in murine model of persistent herpesvirus infection (28), than to the induction of a tolerogenic response. More data need to be gathered to better understand the impact of vertical $\mathrm{HBV}$ infection on humans during the early stages of life.

\section{IMMUNOLOGICAL PARAMETERS IN THE "IMMUNE TOLERANCE" PHASE OF HBV INFECTION}

The existence of an immunotolerance phase of $\mathrm{HBV}$ infection during childhood is supported by clinical and virological manifestations. Since HBV is not directly cytopathic and HBV-specific CD8 T cells control virus spread by killing the infected hepatocytes (29), it is logical to think that the presence/absence of altered ALT levels correlates with the presence/absence of HBV-specific T cells (Figure 1A). Therefore, normality of liver enzymes, detectable in the majority of $\mathrm{HBV}$-infected children, has been interpreted as an indication of a lack of HBV-specific T cell response, while ALT alterations, more likely to occur during adulthood, are interpreted as an "awakening" of HBV-specific immunity. 
In reality, ALT measurement cannot be used as a reliable surrogate of a virus-specific $\mathrm{T}$ cell response. Work in adenovirusinfected mice (30) confirmed that $\mathrm{T}$ cell immunity against hepatocytes could take place without serum ALT elevation. Adoptive transfer of HBV-specific T cells can cause substantial inhibition of HBV replication without ALT increase through cytokine-mediated non-cytopathic virus control (31) and HBV-specific T cells quantification in blood and liver is not proportional to ALT levels (32, 33). Robust liver inflammatory events causing ALT elevations are instead, demonstrated in adult mice and in patients, associated with a liver infiltrate consisting of granulocytes, monocytes, and non-antigen-specific T cells $(32,34,35)$.

A direct demonstration that the "immunotolerance" phase is not associated with an absence of virus-specific $\mathrm{T}$ cell immunity came directly from our recent study of chronic hepatitis $\mathrm{B}$ (CHB)-infected adolescents. Despite having a clinical and virological profile labeled as "immunotolerant," these adolescents displayed a perfectly normal Th1 T cell response and harbored HBV-specific T cells that were actually functionally better than the ones detected in adult CHB patients in the "immune clearance" phase (36).

\section{AGE-DEPENDENT CHANGES IN IMMUNITY AND INFLAMIMATORY EVENTS DURING VIRAL INFECTIONS}

Innate immune responses are not identical during the life of an individual. TLR-mediated immune function has been shown to change in different periods of life (37). The production of antiinflammatory cytokine (e.g., IL-10) is high in preterm infants, and it progressively declines over the first years of life but is superior in children versus adults. In contrast, the production of pro-inflammatory cytokines (e.g., IL-1b, TNF-alpha) steadily increases during early life (37) until it reaches the state of chronic low-grade systemic inflammation called "inflammaging” present in elderly subjects (38).

Consequently, $\mathrm{T}$ cell responses also shift from a Th2/Treg type response in newborns to a more Th1 response in children/adults (15) and with a progressive increase in effector memory $\mathrm{T}$ cell pools. These effector memory $\mathrm{T}$ cells can respond efficiently to a cognate infection and are also sensitive to cytokine-mediated activation (39). The question then arises: can these age-dependent changes in immune functions explain the different virological and inflammatory patterns during the natural history of $\mathrm{HBV}$ infection?

Interestingly, the evidence of the impact of age on pathological processes can also be observed in other infections. Influenza virus infection, for example, can cause death due to an increased inflammatory response in the lung predisposing to bacterial infection (40) in some but not all individuals. Figure 2 shows the data on the incidence of both clinical influenza and pneumonia mortality during the 1918 influenza pandemic in relation to age (40). It is evident that children, despite experiencing a higher rate of clinical influenza, had a much lower mortality rate than young adults. This phenomenon has also been observed in other infections (41). The immunological mechanisms underlying these different outcomes have not been experimentally demonstrated but the common trend is that inflammatory events are less severe in children than in adults. It is certainly intriguing that the "immunotolerant and the

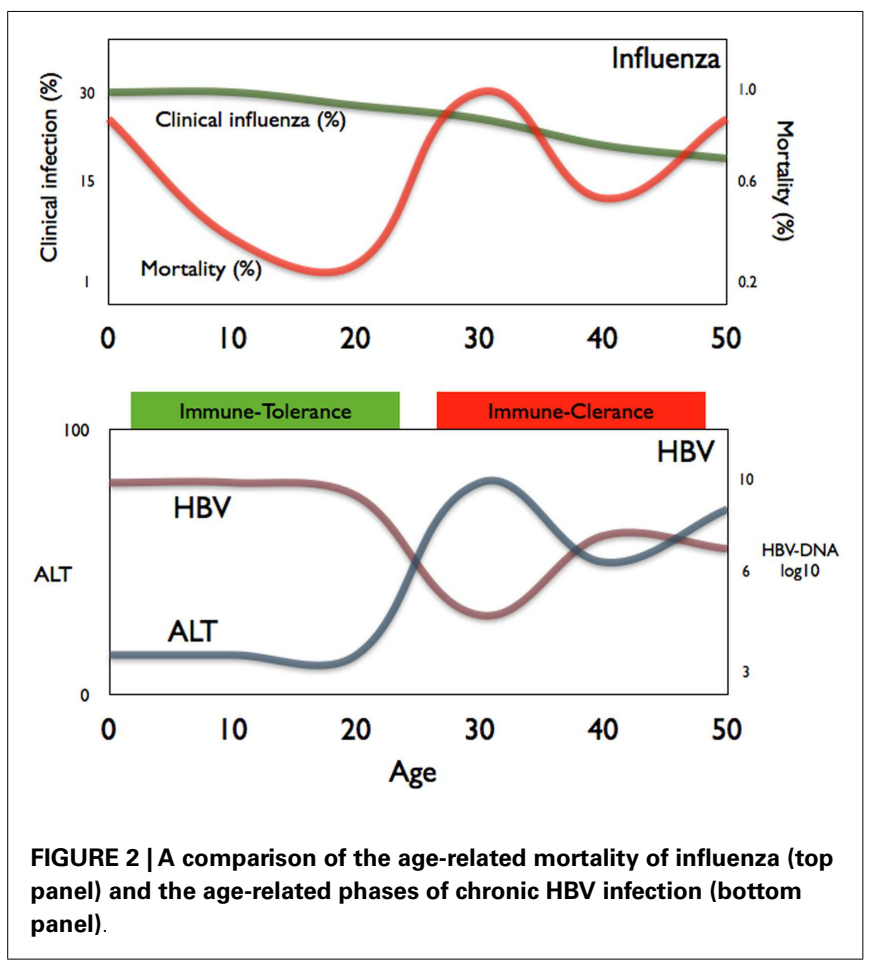

active immune phases" of chronic HBV infection mirrors the different age-related mortality seen in the 1918 influenza pandemic (Figure 2).

\section{IMIMUNOLOGICAL EVENTS DURING HBV INFECTION: AN ALTERNATIVE HYPOTHESIS}

Based on the epidemiological, clinical, and experimental data summarized above, we propose an alternative interpretation of the immune events occurring during natural HBV infection:

(a) HBV transmission at birth is not exclusively followed by persistent infection and characterized by an inability to mount a $\mathrm{HBV}$-specific adaptive immunity. Newborns of $\mathrm{HBV}^{+}$mothers can mount a $\mathrm{HBV}$-specific immune response following vaccination (22), and the detection of $\mathrm{T}$ cells specific for the HBV core and polymerase antigen (antigens not present in the HBV prophylactic vaccine) $(18,19)$ shows that HBV exposure in utero can prime virus-specific T cells. Further studies are needed to define the mechanisms/circumstances underlying this induction. However, the frequent detection of HBV-specific memory $\mathrm{T}$ cells in young, exposed, but uninfected subjects (42) imply that the induction of a specific adaptive immunity after HBV contact at birth or during childhood is not a rare event. However, with the exceptions of very few cases of fulminant hepatitis present at birth (25), HBVspecific adaptive immunity seems to occur in children without symptoms of acute hepatitis. Whether this different clinical phenotype is the result of a quantitative/qualitative defect in $\mathrm{T}$ cell response or a reduced ability of children to mount a pro-inflammatory response needs to be further evaluated. 
(b) The state of high HBV replication and low ALT levels present in young $\mathrm{CHB}$ patients should be termed the "noninflammatory" phase of HBV infection (Figure 1B). Data obtained from young CHB patients (age between 15 and 30 years old) show that, at least in this period, the absence of serological markers of liver inflammation is not associated with an immune profile of general or HBV-specific T cell tolerance (36). Furthermore, clonal hepatocyte repopulation, an indirect measurement of targeted killing of HBV-infected hepatocytes, has been detected in immunotolerant patients (P. Kennedy and Bill Mason, personal communications). The hypothesis is that in children, HBV-specific CD8 T cells might try to contain the HBV infection like in adults but due to the reduced pro-inflammatory cytokine milieu and the limited pool of effector/memory $\mathrm{T}$ cells, they do not trigger the non-specific recruitment of inflammatory cells to the liver.

(c) The immune clearance phase of chronic hepatitis, characterized by altered levels of ALT, fluctuations in the HBV replication levels, and histological signs of liver inflammation, may be better defined as the "inflammatory" phase of $\mathrm{CHB}$ (Figure 1B). The adult's propensity to mount proinflammatory immune reactions might explain the clinical, immunological, and virological profiles of HBV infection in adults. Liver inflammation can be triggered by HBV-specific CD8 T cells, but it is unlikely a direct effect since the extent of liver inflammation is not proportional to the absolute quantity of HBV-specific CD8 T cells. In adult patients, HBV-specific $\mathrm{T}$ cell response is not proportional to liver inflammation (32). Similarly, episodes of hepatic flares (heightened liver inflammation) are observed without any detectable increase of circulating HBV-specific T cells (43) but are instead associated with increased level of chemokines (43) and NK cell activation (44). Changes in liver inflammatory environment might tune the sensitivity of T cells to antigens (45) and this might indirectly increase $\mathrm{HBV}$-specific $\mathrm{T}$ cell activation. Alternatively, liver inflammatory events might derive directly from proinflammatory reactions trigger by different sources, e.g., bacterial products as shown in a model of hepatic steatosis (46). Changes in the intra-hepatic pro-inflammatory environment may explain the fluctuations in HBV replication. IL-1beta and TNF-alpha, the classical pro-inflammatory cytokines, have inhibitory effects on $\operatorname{HBV}(47,48)$ through the activation of cytidine deaminases, enzymes that are highly activated in advanced liver pathologies (49).

There are clinical implications on these alternative interpretations. Firstly, if young $\mathrm{CHB}$ patients can mount $\mathrm{HBV}$ specific immune responses without inducing a full blown proinflammatory reaction, therapies designed to boost HBV-specific immunity (e.g., vaccine therapy, check points inhibitors) (50) are more likely to succeed and will be less damaging in these young patients. Secondly, if we start to evaluate and study $\mathrm{CHB}$ infection in adults in the context of an inflammatory disease rather than a viral induced disease, anti-inflammatory therapies designed to inhibit the liver inflammatory events may prove to be important in controlling HBV infection. The superior efficacy of the anti-platelet therapy in blocking the development of hepatocellular carcinoma in HBV transgenic mice is one such example $(51,52)$.

\section{CONCLUDING REMARKS}

Epidemiological and experimental evidences raised doubts that the natural progression of $\mathrm{CHB}$ can be dictated by a simple quantitative difference in adaptive immunity. The classic view of HBV vertical transmission inevitably causing a phase of HBV-specific immune tolerance, which is lost during adulthood, is not tenable to our increased understanding of the effect of age on the immune response and on the HBV-specific immune events.

We are aware that more experimental data need to be gathered to support the alternative scenarios that we have proposed. Nevertheless, we and others (53) believe that the different clinical phenotypes of HBV infection in children and adults should no longer be described based on (1) the mechanisms that have been exclusively determined in experimental mouse models that do not establish persistent $\mathrm{HBV}$ infection and (2) the clinical observations on the circulating levels of HBV and ALT.

Having said that, additional data need to be gathered especially during the early phases of HBV infection, i.e., from HBV-exposed newborn infants and CHB-infected children, in whom limited studies have been performed. Moving forward, it is of our interest to test whether $\mathrm{HBV}^{+}$children harbor $\mathrm{HBV}$-specific immunity and whether such responses trigger intra-hepatic inflammatory events only in adults. We are also aware of the potential roles of many other components of the immune response that needs to be analyzed; one example is NK cells that are present abundantly in the liver and might have both antiviral and regulatory effects in HBV infection (54).

At the moment, there are still many gaps in the knowledge of $\mathrm{HBV}$ infection and we hope that this opinion article might inspire new avenues of research that can better define the immunopathological processes of this infectious disease that is affecting a considerable part of human population.

\section{ACKNOWLEDGMENTS}

This work was supported by a Singapore Research Translational Investigator (NMRC/STaR/013/2012) to Antonio Bertoletti.

\section{REFERENCES}

1. Liaw Y-F, Chu C-M. Hepatitis B virus infection. Lancet (2009) 373:582-92. doi:10.1016/S0140-6736(09)60207-5

2. Yim HJ, Lok AS-F. Natural history of chronic hepatitis B virus infection: what we knew in 1981 and what we know in 2005. Hepatology (2006) 43:S173-81. doi:10.1002/hep. 20956

3. Bertoletti A, Ferrari C. Innate and adaptive immune responses in chronic hepatitis B virus infections: towards restoration of immune control of viral infection. Gut (2012) 61:1754-64. doi:10.1136/gutjnl-2011-301073

4. Milich DR, Jones JE, Hughes JL, Price J, Raney AK, McLachlan A. Is a function of the secreted hepatitis B E antigen to induce immunologic tolerance in utero? Proc Natl Acad Sci U S A (1990) 87:6599-603. doi:10.1073/pnas.87.17.6599

5. Publicover J, Gaggar A, Nishimura S, Van Horn CM, Goodsell A, Muench MO, et al. Age-dependent hepatic lymphoid organization directs successful immunity to hepatitis B. J Clin Invest (2013) 123:3728-39. doi:10.1172/JCI68182

6. Publicover J, Goodsell A, Nishimura S, Vilarinho S, Wang Z-E, Avanesyan L, et al. IL-21 is pivotal in determining age-dependent effectiveness of immune responses in a mouse model of human hepatitis B. J Clin Invest (2011) 121:1154-62. doi:10.1172/JCI44198

7. Chisari FV, Ferrari C. Hepatitis B virus immunopathogenesis. Annu Rev Immunol (1995) 13:29-60. doi:10.1146/annurev.iy.13.040195.000333 
8. Jo J, Tan AT, Bertoletti A. Murine models and human studies of pathogenesis of chronic hepatitis B. In: Thomas HC, Lok, ASF, Locarnini SA, Zuckerman AJ, editors. Fourth ed. Viral Hepatitis. Oxford, UK: John Wiley \& Sons, Ltd (2013). p. 176-87.

9. Mold JE, Venkatasubrahmanyam S, Burt TD, Michaelsson J, Rivera JM, Galkina $\mathrm{SA}$, et al. Fetal and adult hematopoietic stem cells give rise to distinct $\mathrm{T}$ cell lineages in humans. Science (2010) 330:1695-9. doi:10.1126/science.1196509

10. Zhang X, Mozeleski B, Lemoine S, Dériaud E, Lim A, Zhivaki D, et al. CD4 T cells with effector memory phenotype and function develop in the sterile environment of the fetus. Sci Transl Med (2014) 6:238ra72. doi:10.1126/scitranslmed. 3008748

11. Marchant A, Appay V, Van Der Sande M, Dulphy N, Liesnard C, Kidd M, et al. Mature CD8(+) T lymphocyte response to viral infection during fetal life. J Clin Invest (2003) 111:1747-55. doi:10.1172/JCI17470

12. Vermijlen D, Vermijlen D, Brouwer M, Brouwer M, Donner C, Donner C, et al. Human cytomegalovirus elicits fetal T cell responses in utero. J Exp Med (2010) 207:807-21. doi:10.1084/jem.20090348

13. Luzuriaga K, Holmes D, Hereema A, Wong J, Panicali DL, Sullivan JL. HIV-1specific cytotoxic $\mathrm{T}$ lymphocyte responses in the first year of life. J Immunol (1995) 154:433-43.

14. Netea MG, Quintin J, van der Meer JWM. Trained immunity: a memory for innate host defense. Cell Host Microbe (2011) 9:355-61. doi:10.1016/j.chom. 2011.04.006

15. Levy O. Innate immunity of the newborn: basic mechanisms and clinical correlates. Nat Rev Immunol (2007) 7:379-90. doi:10.1038/nri2075

16. Koumbi LJ, Papadopoulos NG, Anastassiadou V, Machaira M, Kafetzis DA, Papaevangelou V. Dendritic cells in uninfected infants born to hepatitis B viruspositive mothers. Clin Vaccine Immunol (2010) 17:1079-85. doi:10.1128/CVI. 00074-10

17. Guo J, Gao Y, Guo Z, Zhang LR, Wang B, Wang SP. Frequencies of dendritic cells and Toll-like receptor 3 in neonates born to HBsAg-positive mothers with different HBV serological profiles. Epidemiol Infect (2014):1-9. doi:10.1017/S0950268814000624

18. Koumbi L, Bertoletti A, Anastasiadou V, Machaira M, Goh W, Papadopoulos NG, et al. Hepatitis B-specific T helper cell responses in uninfected infants born to HBsAg+/HBeAg- mothers. Cell Mol Immunol (2010) 7:454-8. doi:10.1038/ cmi. 2010.34

19. Komatsu H, Inui A, Sogo T, Hiejima E, Tateno A, Klenerman P, et al. Cellular immunity in children with successful immunoprophylactic treatment for mother-to-child transmission of hepatitis B virus. BMC Infect Dis (2010) 10:103. doi:10.1186/1471-2334-10-103

20. Wang HY, Chien MH, Huang HP, Chang HC, Wu CC, Chen PJ, et al. Distinct hepatitis $\mathrm{B}$ virus dynamics in the immunotolerant and early immunoclearance phases. J Virol (2010) 84:3454-63. doi:10.1128/JVI.02164-09

21. Beasley RP, Hwang LY, Lee GC, Lan CC, Roan CH, Huang FY, et al. Prevention of perinatally transmitted hepatitis $\mathrm{B}$ virus infections with hepatitis B immune globulin and hepatitis B vaccine. Lancet (1983) 2:1099-102. doi:10.1016/S0140-6736(83)90624-4

22. Mackie CO, Buxton JA, Tadwalkar S, Patrick DM. Hepatitis B immunization strategies: timing is everything. Can Med Assoc J (2009) 180:196-202. doi:10.1503/cmaj.081112

23. D’Antiga L, Aw M, Atkins M, Moorat A, Vergani D, Mieli-Vergani G. Combined lamivudine/interferon- $\alpha$ treatment in "immunotolerant" children perinatally infected with hepatitis B: a pilot study. J Pediatr (2006) 148:228.e-33.e. doi:10.1016/j.jpeds.2005.09.020

24. Carey I, D’Antiga L, Bansal S, Longhi MS, Ma Y, Mesa IR, et al. Immune and viral profile from tolerance to hepatitis B surface antigen clearance: a longitudinal study of vertically hepatitis B virus-infected children on combined therapy. J Virol (2011) 85:2416-28. doi:10.1128/JVI.01449-10

25. Chen H-L, Chang C-J, Kong M-S, Huang F-C, Lee H-C, Lin C-C, et al. Pediatric fulminant hepatic failure in endemic areas of hepatitis B infection: 15 years after universal hepatitis B vaccination. Hepatology (2004) 39:58-63. doi: $10.1002 /$ hep. 20006

26. Andrade BB, Santos CJN, Camargo LM, Souza-Neto SM, Reis-Filho A, Clarêncio J, et al. Hepatitis B infection is associated with asymptomatic malaria in the Brazilian Amazon. PLoS One (2011) 6:e19841. doi:10.1371/journal.pone. 0019841
27. Thursz MR, Kwiatkowski D, Torok ME, Allsopp CE, Greenwood BM, Whittle $\mathrm{HC}$, et al. Association of hepatitis B surface antigen carriage with severe malaria in Gambian children. Nat Med (1995) 1:374-5. doi:10.1038/nm0495-374

28. Barton ES, White DW, Cathelyn JS, Brett-McClellan KA, Engle M, Diamond MS, et al. Herpesvirus latency confers symbiotic protection from bacterial infection. Nature (2007) 447:326-9. doi:10.1038/nature05762

29. Thimme R, Wieland S, Steiger C, Ghrayeb J, Reimann KA, Purcell RH, et al. CD8(+) $\mathrm{T}$ cells mediate viral clearance and disease pathogenesis during acute hepatitis B virus infection. J Virol (2003) 77:68-76. doi:10.1128/JVI.77.1.68-76. 2003

30. Stabenow D, Frings M, Trück C, Gärtner K, Förster I, Kurts C, et al. Bioluminescence imaging allows measuring CD8 T cell function in the liver. Hepatology (2010) 51:1430-7. doi:10.1002/hep.23575

31. Guidotti LG, Ishikawa T, Hobbs MV, Matzke B, Schreiber R, Chisari FV. Intracellular inactivation of the hepatitis B virus by cytotoxic T lymphocytes. Immunity (1996) 4:25-36. doi:10.1016/S1074-7613(00)80295-2

32. Maini MK, Boni C, Lee CK, Larrubia JR, Reignat S, Ogg GS, et al. The role of virus-specific CD8(+) cells in liver damage and viral control during persistent hepatitis B virus infection. J Exp Med (2000) 191:1269-80. doi:10.1084/jem.191.8.1269

33. Webster GJM, Reignat S, Brown D, Ogg GS, Jones L, Seneviratne SL, et al. Longitudinal analysis of CD8+ T cells specific for structural and nonstructural hepatitis B virus proteins in patients with chronic hepatitis B: implications for immunotherapy. J Virol (2004) 78:5707-19. doi:10.1128/JVI.78.11.5707-5719. 2004

34. Ando K, Moriyama T, Guidotti LG, Wirth S, Schreiber RD, Schlicht HJ, et al. Mechanisms of class I restricted immunopathology. A transgenic mouse model of fulminant hepatitis. J Exp Med (1993) 178:1541-54. doi:10.1084/jem.178.5. 1541

35. Sitia G, Isogawa M, Kakimi K, Wieland SF, Chisari FV, Guidotti LG. Depletion of neutrophils blocks the recruitment of antigen-nonspecific cells into the liver without affecting the antiviral activity of hepatitis B virus-specific cytotoxic T lymphocytes. Proc Natl Acad Sci U S A (2002) 99:13717-22. doi:10.1073/pnas.172521999

36. Kennedy PTF, Sandalova E, Jo J, Gill U, Ushiro-Lumb I, Tan AT, et al. Preserved Tcell function in children and young adults with immune-tolerant chronic hepatitis B. Gastroenterology (2012) 143:637-45. doi:10.1053/j.gastro.2012.06.009

37. Kollmann TR, Levy O, Montgomery RR, Goriely S. Innate immune function by toll-like receptors: distinct responses in newborns and the elderly. Immunity (2012) 37:771-83. doi:10.1016/j.immuni.2012.10.014

38. Shaw AC, Joshi S, Greenwood H, Panda A, Lord JM. Aging of the innate immune system. Curr Opin Immunol (2010) 22:507-13. doi:10.1016/j.coi.2010.05.003

39. Geginat J, Sallusto F, Lanzavecchia A. Cytokine-driven proliferation and differentiation of human naive, central memory, and effector memory CD4(+) T cells. J Exp Med (2001) 194:1711-9. doi:10.1084/jem.194.12.1711

40. Fedson DS. Was bacterial pneumonia the predominant cause of death in the 1918-1919 influenza pandemic? J Infect Dis (2009) 199:1408-9. doi:10.1086/ 597621

41. Fedson DS. Treating influenza with statins and other immunomodulatory agents. Antiviral Res (2013) 99:417-35. doi:10.1016/j.antiviral.2013.06.018

42. Tan AT, Sodsai P, Chia A, Moreau E, Chng MHY, Tham CYL, et al. Immunoprevalence and immunodominance of $\mathrm{HLA}-\mathrm{Cw}^{\star} 0801$-restricted $\mathrm{T}$ cell response targeting the hepatitis B virus envelope transmembrane region. J Virol (2013) 88:1332-41. doi:10.1128/JVI.02600-13

43. Tan AT, Koh S, Goh W, Zhe HY, Gehring AJ, Lim SG, et al. A longitudinal analysis of innate and adaptive immune profile during hepatic flares in chronic hepatitis B. J Hepatol (2010) 52:330-9. doi:10.1016/j.jhep.2009.12.015

44. Dunn C, Brunetto M, Reynolds G, Christophides T, Kennedy PT, Lampertico $\mathrm{P}$, et al. Cytokines induced during chronic hepatitis B virus infection promote a pathway for NK cell-mediated liver damage. J Exp Med (2007) 204:667-80. doi:10.1084/jem.20061287

45. Richer MJ, Nolz JC, Harty JT. Pathogen-specific inflammatory milieux tune the antigen sensitivity of CD8. Immunity (2013) 38:140-52. doi:10.1016/j.immuni. 2012.09.017

46. Henao-Mejia J, Elinav E, Jin C, Hao L, Mehal WZ, Strowig T, et al. Inflammasome-mediated dysbiosis regulates progression of NAFLD and obesity. Nature (2012) 482(7384):179-85. doi:10.1038/nature10809 
47. Puro R, Schneider RJ. Tumor necrosis factor activates a conserved innate antiviral response to hepatitis $\mathrm{B}$ virus that destabilizes nucleocapsids and reduces nuclear viral DNA. J Virol (2007) 81:7351-62. doi:10.1128/JVI.00554-07

48. Watashi K, Liang G, Iwamoto M, Marusawa H, Uchida N, Daito T, et al. Interleukin-1 and tumor necrosis factor- $\alpha$ trigger restriction of hepatitis $B$ virus infection via a cytidine deaminase activation-induced cytidine deaminase (AID). J Biol Chem (2013) 288:31715-27. doi:10.1074/jbc.M113. 501122

49. Vartanian J-P, Henry M, Marchio A, Suspène R, Aynaud M-M, Guétard D, et al. Massive APOBEC3 editing of hepatitis B viral DNA in cirrhosis. PLoS Pathog (2010) 6:e1000928. doi:10.1371/journal.ppat.1000928

50. Bertoletti A, Gehring AJ. Immune therapeutic strategies in chronic hepatitis B virus infection: virus or inflammation control? PLoS Pathog (2013) 9:e1003784. doi:10.1371/journal.ppat.1003784

51. Sitia G, Iannacone M, Muller S, Bianchi ME, Guidotti LG. Treatment with HMGB1 inhibitors diminishes CTL-induced liver disease in HBV transgenic mice. J Leukoc Biol (2006) 81:100-7. doi:10.1189/jlb.0306173

52. Sitia G, Aiolfi R, Di Lucia P, Mainetti M, Fiocchi A, Mingozzi F, et al. Antiplatelet therapy prevents hepatocellular carcinoma and improves survival in a mouse model of chronic hepatitis B. Proc Natl Acad Sci U S A (2012) 109:E2165-72. doi:10.1073/pnas.1209182109
53. Zoulim F, Mason WS. Reasons to consider earlier treatment of chronic HBV infections. Gut (2012) 61:333-6. doi:10.1136/gutjnl-2011-300937

54. Maini MK, Peppa D. NK cells: a double-edged sword in chronic hepatitis B virus infection. Front Immunol (2013) 4:57. doi:10.3389/fimmu.2013.00057

Conflict of Interest Statement: The authors declare that the research was conducted in the absence of any commercial or financial relationships that could be construed as a potential conflict of interest.

Received: 18 June 2014; accepted: 31 August 2014; published online: 23 September 2014. Citation: Bertoletti A and Hong M (2014) Age-dependent immune events during HBV infection from birth to adulthood: an alternative interpretation. Front. Immunol. 5:441. doi: 10.3389/fimmu.2014.00441

This article was submitted to Immunotherapies and Vaccines, a section of the journal Frontiers in Immunology.

Copyright $\odot 2014$ Bertoletti and Hong. This is an open-access article distributed under the terms of the Creative Commons Attribution License (CC BY). The use, distribution or reproduction in other forums is permitted, provided the original author(s) or licensor are credited and that the original publication in this journal is cited, in accordance with accepted academic practice. No use, distribution or reproduction is permitted which does not comply with these terms. 